\title{
Successful Piglet Production in a Chemically Defined System for In-vitro Production of Porcine Embryos: Dibutyryl Cyclic AMP and Epidermal Growth Factor-family Peptides Support In-vitro Maturation of Oocytes in the Absence of Gonadotropins
}

\author{
Yuka AKAKI ${ }^{1)}$, Koji YOSHIOKA ${ }^{2)}$, Michiko NOGUCHI'), Hiroyoshi HOSHI ${ }^{3)}$ and \\ Hiroaki FUNAHASHI ${ }^{1)}$
}

${ }^{1)}$ Department of Animal Science, Okayama University, Okayama 700-8530, 2) Research Team for Production Diseases, National Institute of Animal Health, Tsukuba 305-0856 and ${ }^{3)}$ Research Institute for the Functional Peptides, Yamagata 9900823, Japan

\begin{abstract}
To induce meiotic resumption of porcine oocytes, it is thought to be necessary to expose the cumulus-oocyte complexes (COCs) to gonadotropins during in-vitro maturation (IVM). However, the detailed mechanism of meiotic resumption by gonadotropins is still unknown, and successful piglet production has not been reported by using oocytes matured in gonadotropin-free media and fertilized in vitro. The present study was undertaken to examine the combinational effects of epidermal growth factor (EGF)-family members and dibutyryl cyclic AMP (cAMP) in a chemically defined medium on IVM of porcine oocytes and the developmental competence following in vitro fertilization (IVF). The basic IVM medium was a chemically defined medium, modified porcine oocyte medium (mPOM). Supplementation of the IVM medium with 10 or $1000 \mathrm{ng} / \mathrm{ml} \mathrm{EGF}$, amphiregulin and betacellulin during the whole IVM period, except for $10 \mathrm{ng} / \mathrm{ml}$ amphiregulin, increased the percentage of oocytes maturing to the metaphaseII stage. When COCs were exposed to both dibutyryl cAMP and EGF-family members during the first 20-h of IVM and then culture was continued in the absence of EGF-family members and dibutyryl cAMP, the incidence of metaphase-II oocytes was significantly increased and was not different from that of oocytes cultured in a standard IVM system with gonadotropins. The developmental competence of the oocytes to the blastocyst stage following IVF was no different from that of control oocytes matured with gonadotropins. When these blastocysts were transferred into the uterine horn of three recipients, all of gilts became pregnant and delivered a total of 11 piglets. These observations indicate that supplementation of a chemically defined maturation medium with EGF-family members and dibutyryl cAMP during the first $20 \mathrm{~h}$ of IVM can support well the meiotic progress and developmental competence of porcine oocytes.
\end{abstract}

Key words: Cyclic AMP (cAMP), Epidermal growth factor (EGF), In vitro maturation, Oocyte, Pig

(J. Reprod. Dev. 55: 446-453, 2009)

\begin{abstract}
S uccessful in-vitro production of porcine embryos has the potential to provide an effective system for mass production of embryos for better understanding of the physiology of embryonic development and animal reproductive technologies, including production of transgenic and/or cloned animals [1, 2]. Relatively efficient systems for in-vitro production of porcine embryos have already been developed, but they contain materials derived from organisms, such as porcine follicular fluid and bovine serum albumin, in the culture media $[3,4]$. Chemically defined media, which only known chemicals, but none derived from animals, yeast or plants, should be useful in clarifying the mechanism of interactive communication between the oocyte and the surrounding cumulus cells during meiosis, the oocyte reaction following sperm penetration and early development. Furthermore, application of a defined system for in-vitro embryo production would be good for a quality control against the risk of viral contamination during culture. Recently, defined media for in vitro production of porcine embryos using a single basic medium have been developed that enable suc-
\end{abstract}

Accepted for publication: April 9, 2009

Published online in J-STAGE: May 14, 2009

Correspondence: H Funahashi (e-mail: hirofun@cc.okayama-u.ac.jp) cessful blastocyst formation [5]. These chemically defined media include a porcine oocyte medium (POM) for in-vitro maturation (IVM) [5], porcine gamete medium (PGM) for in-vitro fertilization (IVF) $[6,7]$ and porcine zygote medium (PZM) for in vitro culture (IVC) of zygotes based on the composition of porcine oviductal fluid [8]. Even in this system, however, gonadotropins derived from organisms were included in the maturation medium [5]. Although recombinant gonadotropins are commercially available, the downstream mechanism of gonadotropins to induce meiotic resumption and development to the metaphase-II stage is still unknown in chemically defined media. Furthermore, successful piglet production has not been reported using oocytes matured in gonadotropin-free media, whereas, very recently, it has been reported that porcine oocytes can undergo meiosis under gonadotropin-free conditions [9, 10].

Unlike bovine, porcine COCs need to be exposed to gonadotropins for resumption and processing of meiosis [11]. FSH stimulation induces the expression of LH receptor in cumulus cells, and binding of $\mathrm{LH}$ to the receptor induces an increase in the cyclic AMP (cAMP) level and acceleration of meiotic resumption in oocytes [12]. LH stimulation induces a transient and sequential 
expression of epidermal growth factor (EGF) family members, amphiregulin, epiregulin and betacellulin, in rodents [13], horses [14] and humans [15]. These EGF family peptides seem to mediate LH stimulation of oocyte maturation in mice [13, 16] and rats [17]. Therefore, although supplementation with EGF during IVM in the presence of porcine follicular fluid and hormonal supplements does not affect the cumulus expansion, nuclear maturation or developmental competence of oocytes [18], it may stimulate the meiotic resumption of oocytes. Furthermore, exposure of COC to dibutyryl cAMP and gonadotropins only for the first $20 \mathrm{~h}$ of culture for IVM accelerate meiotic resumption of oocytes and improves developmental competence compared with COCs exposed to only gonadotropins $[19,20]$. Recently, when exposure of COCs in the presence of fetal bovine serum to an inhibitor of phosphodiesterase (PDE), 3-isobutyl-1-methylxanthine, only for the first $20 \mathrm{~h}$ of culture well supported meiotic maturation to the metaphase-II stage [10]. Therefore, application of chemicals affecting the intracellular cAMP level and/or EGF signaling pathway may successfully support IVM of porcine oocytes in a gonadotropin-free medium

In the present study, we examined the effects of EGF-family peptides alone or in combination with dibutyryl cAMP in maturation medium on meiotic maturation of porcine oocytes. Furthermore, we examined the developmental competence of the oocytes and successfully produced, for the first time, piglets from oocytes matured in a gonadotropin-free medium and fertilized and developed to the blastocyst stage in chemically defined media.

\section{Materials and Methods}

\section{Chemicals and culture media}

Potassium chloride, $\mathrm{KH}_{2} \mathrm{PO}_{4}, \mathrm{MgCl}_{2} \cdot 6 \mathrm{H}_{2} \mathrm{O}, \mathrm{CaCl}_{2} \cdot 2 \mathrm{H}_{2} \mathrm{O}$, sodium citrate and citric acid were purchased from Ishizu Pharmaceutical (Osaka, Japan). Sodium chloride and paraffin liquid were obtained from Nacalai Tesque (Kyoto, Japan). Unless specified, other chemicals were purchased from Sigma Aldrich Japan (Tokyo, Japan).

The medium used for collecting and washing COCs was modified TL-HEPES-PVA medium composed of $114 \mathrm{mM} \mathrm{NaCl}, 3.2$ $\mathrm{mM} \mathrm{KCl,} 2 \mathrm{mM} \mathrm{NaHCO}, 0.34 \mathrm{mM} \mathrm{KH}_{2} \mathrm{PO}_{4}, 10 \mathrm{mM}$ Na-lactate, $0.5 \mathrm{mM} \mathrm{MgCl}_{2} \cdot 6 \mathrm{H}_{2} \mathrm{O}, 2 \mathrm{mM} \mathrm{CaCl} 2 \cdot 2 \mathrm{H}_{2} \mathrm{O}, 10 \mathrm{mM}$ HEPES, 0.2 $\mathrm{mM}$ Na-pyruvate, $12 \mathrm{mM}$ sorbitol, $0.1 \%$ (w/v) polyvinylalcohol, $25 \mu \mathrm{g} / \mathrm{ml}$ gentamicin and $65 \mu \mathrm{g} / \mathrm{ml}$ potassium penicillin $\mathrm{G}$. The basic IVM medium used was a BSA-free chemically defined medium, POM (Research Institute for the Functional Peptides, Yamagata, Japan), supplemented with $50 \mu \mathrm{M}$ beta-mercaptoethanol (mPOM). This IVM medium well supports blastocyst development following IVF if gonadotropins are added during IVM [5]. The chemically defined media for IVF and in vitro development to the blastocyst stage were PGM-tac4 (Research Institute for the Functional Peptides, Yamagata, Japan) and PZM-5 (Research Institute for the Functional Peptides, Yamagata, Japan), respectively. All media (except for modified TL-HEPES-PVA) were equilibrated at $39 \mathrm{C}$ in an atmosphere of $5 \% \mathrm{CO}_{2}$ in air overnight prior to use (only PGM-tac4 was under paraffin liquid).

\section{Preparation and culture of cumulus-oocyte complexes}

Ovaries were collected from slaughtered prepubertal gilts at a local abattoir and transported to the laboratory in $0.9 \% \mathrm{NaCl}$ containing $75 \mu \mathrm{g} / \mathrm{ml}$ potassium penicillin $\mathrm{G}$ and $50 \mu \mathrm{g} / \mathrm{ml}$ streptomycin sulphate. Using an 18-gauge needle and a disposable 10-ml syringe, COCs were aspirated from antral follicles (3 to $6 \mathrm{~mm}$ in diameter) on the surface of the ovaries and washed three times with modified TL-HEPES-PVA medium at room temperature (25 C) [19]. Forty to fifty COCs with uniform ooplasm and a compact cumulus cell mass were washed three times with IVM medium. These complexes were subsequently cultured in $500 \mu \mathrm{l}$ of IVM medium for a total of $44 \mathrm{~h}$ at $39 \mathrm{C}$ in an atmosphere of $5 \% \mathrm{CO}_{2}$ in air. After IVM culture, the oocytes were stripped of cumulus cells by pipetting with $0.1 \%(\mathrm{w} / \mathrm{v})$ hyaluronidase and evaluated for nuclear maturation. Some of the oocytes were washed with modified TL-HEPES-PVA three times, mounted, fixed for $48 \mathrm{~h}$ or more in $25 \%(\mathrm{v} / \mathrm{v})$ acetic acid-alcohol at room temperature, stained with $1 \%(\mathrm{w} / \mathrm{v})$ orcein in $45 \%(\mathrm{v} / \mathrm{v})$ acetic acid and then examined under a phase-contrast microscope at $400 \times$ magnification.

\section{Preparation of fresh boar spermatozoa and in vitro fertilization}

Semen-rich fractions (30 to $50 \mathrm{ml}$ ) were collected from boars, three Birkshire and one Duroc, by the glove-hand method at a local experimental station and were diluted 4 times with modified Modena solution [21]. The diluted semen samples were transported to the laboratory within $2 \mathrm{~h}$ of collection. After washing once by centrifugation at $750 \mathrm{~g}$ for $3 \mathrm{~min}$, the spermatozoa were resuspended at a concentration of $1 \times 10^{8}$ cells $/ \mathrm{ml}$ in modified Modena solution containing $5 \mathrm{mM}$ cysteine and $20 \%$ (v/v) boar seminal plasma. The diluted spermatozoa were used for IVF immediately or after storage overnight at $15 \mathrm{C}$. When a diluted sperm specimen was stored overnight, the sample was cooled down from room temperature to $15 \mathrm{C}$ for $4 \mathrm{~h}$ and then kept at the same temperature. Just before use, the stored spermatozoa were placed at room temperature for 15 to $20 \mathrm{~min}$, washed three times by centrifugation at $750 \mathrm{~g}$ for $3 \mathrm{~min}$ with modified TL-HEPES-PVA solution and then resuspended at a concentration of $1 \times 10^{8}$ cells $/ \mathrm{ml}$ in PGM-tac4.

After dilution to $1 \times 10^{6}$ cells/ml with PGM-tac4, fifty microliters of diluted sperm suspension was inseminated in the same volume of PGM-tac4. Thirty denuded oocytes were co-cultured with spermatozoa in a 100- $\mu$ l droplet of PGM-tac4 under paraffin oil for a total of $8 \mathrm{~h}$ at $39 \mathrm{C}$ in an atmosphere of $5 \% \mathrm{CO}_{2}$ in air. At $8 \mathrm{~h}$ after insemination, some of the cultured eggs were fixed, stained with $1 \%(\mathrm{w} / \mathrm{v})$ orcein and examined at $200 \times$ and $400 \times$ magnification. Oocytes were designated as penetrated when they had at least one sperm head, a decondensed sperm nucleus or a male pronucleus and corresponding sperm tail in the vitellus.

Just after co-culture with spermatozoa, some of the oocytes were incubated in $500 \mu \mathrm{l}$ of PZM-5 for 7 days at $39 \mathrm{C}$ in an atmosphere of $5 \% \mathrm{CO}_{2}$ in air or for 5 days at $39 \mathrm{C}$ in an atmosphere of $5 \% \mathrm{CO}_{2}$, $5 \% \mathrm{O}_{2}$ and $90 \% \mathrm{~N}_{2}$ (in the embryo transfer experiment). Cleavage and morula/blastocyst formation of the oocytes were examined on Day 2 and Days 5 or 7 of culture, respectively. 


\section{Surgical embryo transfer of IVM-IVF blastocysts}

After culture in an atmosphere of $5 \% \mathrm{CO}_{2}, 5 \% \mathrm{O}_{2}$ and $90 \% \mathrm{~N}_{2}$ for 5 days, IVF embryos that developed to the blastocyst stage were washed with PXM-Hepes medium [5] three times and then transferred with the same medium into the uteri of recipients. According to a previous report [6], luteolysis of recipient cross bred gilts ([Landrace $\times$ Large White] $\times$ Duroc, 7 mo old, 96-112 kg body weight) was induced by intramuscular injections of prostaglandin F2 $\alpha$, as 15 mg dinoprost (Panacelan Hi; Meiji Seika, Tokyo, Japan) twice daily for 3 days during the functional luteal phase. Ovulation was induced by intramuscular injections 750 IU of hCG (Puberogen; Novartis Animal Health, Tokyo, Japan) 5 days after start of the prostaglandin F2 $\alpha$ treatments. Day- 5 embryos that developed to blastocysts were surgically transferred into the uteri of 3 recipients (18-19 blastocysts/recipient) 5 days after hCG injection. Pregnancy diagnosis was carried out by ultrasonography 21 days following hCG injection. Gilts considered to be pregnant were allowed to continue to full term, and the gestation lengths, litter sizes and body weights of the piglets at birth were examined. All animal-related procedures followed in this study were approved by the Institutional Care and Use Committee of the Laboratory Animals of the National Institute of Animal Health (protocol No. 08-003).

\section{Experimental design}

Experiment 1: To determine the effect of EGF and EGF-family peptides on resumption of oocyte meiosis, COCs were cultured for $44 \mathrm{~h}$ in gonadotropin-free mPOM with or without EGF, amphiregulin or betacellulin at 10 or $1000 \mathrm{ng} / \mathrm{ml}$, denuded and then fixed to observe meiotic status.

Experiment 2: To examine whether the effect of EGF on the resumption of oocyte meiosis is amplified by a combination with amphiregulin and/or betacellulin, COCs were cultured for $44 \mathrm{~h}$ in IVM medium with EGF alone or with EGF plus amphiregulin and/ or betacellulin. The meiotic status of the oocytes was examined at the end of IVM culture.

Experiment 3: The combination effect of dibutyryl cAMP with EGF alone or EGF plus amphiregulin on meiotic resumption in oocytes was evaluated. COCs were cultured for $20 \mathrm{~h}$ in gonadotropin-free mPOM with dibutyryl cAMP alone or with dibutyryl cAMP plus EGF or plus EGF and amphiregulin and then cultured for $24 \mathrm{~h}$ in gonadotropin-free mPOM without dibutyryl cAMP,
EGF and amphiregulin. As positive controls, some COCs were cultured in IVM medium supplemented with gonadotropins (10 iu/ $\mathrm{ml} \mathrm{eCG}$ and $10 \mathrm{iu} / \mathrm{ml} \mathrm{hCG)} \mathrm{and} 1 \mathrm{mM}$ dibutyryl cAMP for $20 \mathrm{~h}$ and then in unsupplemented medium for an additional $24 \mathrm{~h}[19,22]$. The meiotic status of the oocytes was examined at the end of IVM culture.

Experiment 4: To examine the effect of dibutyryl cAMP plus EGF and amphiregulin on the meiotic resumption of cumulus-free oocytes, denuded oocytes were exposed to dibutyryl cAMP plus EGF and amphiregulin for the first $20 \mathrm{~h}$ of IVM and then culture was continued in fresh mPOM for a further $24 \mathrm{~h}$. At the end of IVM culture, the meiotic status of the oocytes was examined.

Experiment 5: The developmental competence of oocytes exposed to dibutyryl cAMP plus EGF and amphiregulin for the first $20 \mathrm{~h}$ of IVM to the blastocyst stage was examined following IVF and culture in PZM-5 for 7 days at $39 \mathrm{C}$ in an atmosphere of $5 \%$ $\mathrm{CO}_{2}$ in air. Furthermore, the developmental competence of the oocytes to full term was also examined following IVF. IVF embryos were cultured in PZM-5 for 5 days at $39 \mathrm{C}$ in an atmosphere of $5 \% \mathrm{CO}_{2}, 5 \% \mathrm{O}_{2}$ and $90 \% \mathrm{~N}_{2}$. Only embryos that developed to the blastocyst stage were surgically transferred to the uteri of recipient gilts (18-19 blastocysts/recipient).

\section{Statistical analysis}

All oocytes were randomly distributed within each experimental group, and each experiment was repeated at least 3 times. All percentage data were subjected to arcsine transformation before statistical analysis. Statistical analyses of results from 3-7 replicates were used for treatment comparisons and carried out by analysis of variance (ANOVA) using the JMP 5.0 (SAS Institute, Cary, NC, USA) program. If the P value was smaller than 0.05 in ANOVA, the Tukey-Kramer HSD test was performed using the same program. All data were expressed as means \pm S.E.M. $\mathrm{P} \leq 0.05$ was considered to be statistically significant.

\section{Results}

Effect of EGF, amphiregulin and betacellulin on resumption of meiosis (Exp. 1)

As shown in Table 1, with the exception of $10 \mathrm{ng} / \mathrm{ml}$ amphiregulin, the presence of EGF, amphiregulin and betacellulin at $10 \mathrm{ng} / \mathrm{ml}$ and $1000 \mathrm{ng} / \mathrm{ml}$ in maturation medium increased the incidence of

Table 1. Effect of EGF-family peptides in a gonadotropin-free medium on the resumption of meiosis in oocytes*

\begin{tabular}{|c|c|c|c|c|c|c|c|}
\hline $\begin{array}{l}\text { EGF-family } \\
\text { peptides }\end{array}$ & $\begin{array}{l}\text { Concentration } \\
\text { (ng/ml) }\end{array}$ & $\begin{array}{l}\text { No. of oocytes } \\
\text { examined* }\end{array}$ & $\begin{array}{c}\% * * \text { oocytes } \\
\text { completing GVBD }\end{array}$ & $\begin{array}{c}\text { \%** Pro M-I } \\
\text { oocytes }\end{array}$ & $\begin{array}{l}\% * * \text { M-I } \\
\text { oocytes }\end{array}$ & $\begin{array}{c}\% * * \text { A-I/T-I } \\
\text { oocytes }\end{array}$ & $\begin{array}{c}\text { \%** M-II } \\
\text { oocytes }\end{array}$ \\
\hline None (control) & 0 & 115 & $13.9 \pm 1.4^{\mathrm{a}}$ & $1.8 \pm 1.0$ & $2.6 \pm 1.7$ & $0 \pm 0$ & $9.6 \pm 2.2^{\mathrm{a}}$ \\
\hline \multirow[t]{2}{*}{ EGF } & 10 & 114 & $37.9 \pm 5.1^{\mathrm{b}}$ & $0.8 \pm 0.8$ & $7.1 \pm 1.5$ & $0.9 \pm 0.9$ & $29.1 \pm 5.3^{\mathrm{b}}$ \\
\hline & 1000 & 112 & $47.3 \pm 3.9^{b}$ & $0 \pm 0$ & $7.2 \pm 2.1$ & $3.5 \pm 2.0$ & $36.7 \pm 5.8^{b}$ \\
\hline \multirow[t]{2}{*}{ Amphiregulin } & 10 & 118 & $16.1 \pm 1.7^{\mathrm{a}}$ & $1.7 \pm 1.7$ & $4.2 \pm 2.1$ & $1.7 \pm 1.7$ & $8.5 \pm 2.2^{\mathrm{a}}$ \\
\hline & 1000 & 113 & $42.5 \pm 8.1^{b}$ & $0.9 \pm 0.9$ & $8.9 \pm 2.3$ & $2.6 \pm 1.7$ & $30.1 \pm 6.6^{\mathrm{b}}$ \\
\hline \multirow[t]{2}{*}{ Betacellulin } & 10 & 113 & $48.3 \pm 5.0^{\mathrm{b}}$ & $0 \pm 0$ & $4.6 \pm 1.8$ & $4.4 \pm 0.9$ & $39.3 \pm 7.2^{\mathrm{b}}$ \\
\hline & 1000 & 114 & $37.7 \pm 4.9^{b}$ & $0.9 \pm 0.9$ & $4.4 \pm 0.8$ & $1.8 \pm 1.8$ & $30.7 \pm 6.7^{b}$ \\
\hline
\end{tabular}

* COCs were cultured for $44 \mathrm{~h}$ in gonadotropin-free mPOM. EGF-family peptides (EGF, amphiregulin, betacellulin) were added at $0,10 \mathrm{or} 1000 \mathrm{ng} / \mathrm{ml}$ for the whole culture period. **Percentage based on the total number of oocytes examined. Data are presented as means \pm S.E.M. of four replicated experiments. Values with different superscripts within the same column are significantly different $(\mathrm{P}<0.05)$. 
Table 2. Effect of combination of EGF-family peptides in a gonadotropin-free medium on in-vitro maturation of oocytes*

\begin{tabular}{|c|c|c|c|c|c|c|}
\hline EGF-family peptides & $\begin{array}{l}\text { No. of oocytes } \\
\text { examined* }\end{array}$ & $\begin{array}{c}\text { \%** oocytes } \\
\text { completing GVBD }\end{array}$ & $\begin{array}{c}\% * * \text { Pro M-I } \\
\text { oocytes }\end{array}$ & $\begin{array}{l}\text { \%** M-I } \\
\text { oocytes }\end{array}$ & $\begin{array}{c}\% * * \text { A-I/T-I } \\
\text { oocytes }\end{array}$ & $\begin{array}{l}\text { \%** M-II } \\
\text { oocytes }\end{array}$ \\
\hline None (control) & 115 & $14.8 \pm 1.6^{\mathrm{a}}$ & $1.8 \pm 1.0$ & $5.2 \pm 2.2$ & $0 \pm 0$ & $7.9 \pm 1.7^{\mathrm{a}}$ \\
\hline EGF & 114 & $39.6 \pm 3.6^{\mathrm{b}}$ & $0.8 \pm 0.8$ & $7.1 \pm 1.5$ & $0 \pm 0$ & $31.7 \pm 3.0^{\mathrm{b}}$ \\
\hline EGF + amphiregulin & 116 & $52.1 \pm 3.9^{b}$ & $1.9 \pm 1.2$ & $3.5 \pm 1.6$ & $1.3 \pm 1.3$ & $45.8 \pm 3.3^{c}$ \\
\hline EGF + betacellulin & 103 & $50.6 \pm 7.0^{\mathrm{b}}$ & $0.7 \pm 0.7$ & $1.4 \pm 0.9$ & $1.2 \pm 1.2$ & $46.1 \pm 7.9^{c}$ \\
\hline EGF + amphiregulin + betacellulin & 120 & $53.3 \pm 2.6^{\mathrm{b}}$ & $0.9 \pm 0.9$ & $9.0 \pm 2.6$ & $2.6 \pm 1.7$ & $40.8 \pm 1.4^{\mathrm{bc}}$ \\
\hline
\end{tabular}

* COCs were cultured for $44 \mathrm{~h}$ in gonadotropin-free mPOM. EGF-family peptides (EGF, $10 \mathrm{ng} / \mathrm{ml}$; amphiregulin, $1000 \mathrm{ng} / \mathrm{ml}$; betacellulin, $10 \mathrm{ng} / \mathrm{ml}$ ) were added for the whole culture period. **Percentage based on the total number of oocytes examined. Data are presented as means \pm S.E.M. of four replicated experiments. Values with different superscripts within the same column are significantly different $(\mathrm{P}<0.05)$.

Table 3. Effect of combination of EGF-family peptides with dibutyryl cAMP in a gonadotropin-free medium on in-vitro maturation of oocytes*

\begin{tabular}{|c|c|c|c|c|c|c|}
\hline Supplements & $\begin{array}{l}\text { o. of oocytes } \\
\text { examined* }\end{array}$ & $\begin{array}{c}\text { \%** oocytes } \\
\text { completing GVBD }\end{array}$ & $\begin{array}{c}\text { \%** Pro M-I } \\
\text { oocytes }\end{array}$ & $\begin{array}{l}\%^{* *} \text { M-I } \\
\text { oocytes }\end{array}$ & $\begin{array}{c}\text { \%** A-I/T-I } \\
\text { oocytes }\end{array}$ & $\begin{array}{l}\% * * \text { M-II } \\
\text { oocytes }\end{array}$ \\
\hline None (negative control) & 163 & $26.6 \pm 5.9^{\mathrm{a}}$ & $1.8 \pm 1.8$ & $5.1 \pm 1.4$ & $0 \pm 0$ & $19.8 \pm 5.4^{\mathrm{a}}$ \\
\hline EGF & 176 & $46.6 \pm 2.9^{b}$ & $1.1 \pm 0.7$ & $5.9 \pm 2.6$ & $1.6 \pm 0.7$ & $38.0 \pm 4.1^{\mathrm{b}}$ \\
\hline Amphiregulin & 175 & $41.9 \pm 4.3^{\mathrm{b}}$ & $2.1 \pm 1.4$ & $2.2 \pm 1.1$ & $0.5 \pm 0.5$ & $37.1 \pm 2.7^{\mathrm{b}}$ \\
\hline Dibutyryl cAMP & 147 & $64.2 \pm 5.2^{c}$ & $4.2 \pm 2.4$ & $10.4 \pm 3.5$ & $3.5 \pm 1.2$ & $46.1 \pm 4.9^{b}$ \\
\hline EGF + dibutyryl cAMP & 180 & $83.9 \pm 3.1^{\mathrm{d}}$ & $0.6 \pm 0.6$ & $7.2 \pm 1.5$ & $3.8 \pm 1.8$ & $71.2 \pm 3.8^{c}$ \\
\hline EGF + amphiregulin + dibutyryl cAMP & 182 & $87.8 \pm 2.0^{\text {de }}$ & $0.6 \pm 0.6$ & $6.0 \pm 2.0$ & $2.8 \pm 1.4$ & $78.4 \pm 3.5^{c}$ \\
\hline Positive control (Gns + dibutyryl cAMP) & 194 & $96.7 \pm 0.9^{\mathrm{e}}$ & $2.7 \pm 1.4$ & $10.9 \pm 1.8$ & $1.6 \pm 1.2$ & $81.4 \pm 2.8^{\mathrm{c}}$ \\
\hline
\end{tabular}

* COCs were cultured for $44 \mathrm{~h}$ in gonadotropin-free mPOM. EGF-family peptides (10 ng/ml EGF, $1000 \mathrm{ng} / \mathrm{ml}$ amphiregulin) and dibutyryl cAMP (1 mM) were added only for the first $20 \mathrm{~h}$ of culture. As a positive control, gonadotropins (Gns; $10 \mathrm{U} / \mathrm{ml} \mathrm{eCG}$ and $10 \mathrm{U} / \mathrm{ml}$ hCG) and dibutyryl cAMP (1 mM) were added only for the first $20 \mathrm{~h}$ of culture. ${ }^{* *}$ Percentage based on the total number of oocytes examined. Data are presented as means \pm S.E.M. of six replicated experiments. Values with different superscripts within the same column are significantly different $(\mathrm{P}<0.05)$.

oocytes with induced meiotic resumption and development to the metaphase-II stage compared with the controls. However, there were no differences in the incidences of oocytes that completed germinal vesicle breakdown (GVBD) and of oocytes that matured to the metaphase-II stage among the groups supplemented EGF (10 $\mathrm{ng} / \mathrm{ml}$ and $1000 \mathrm{ng} / \mathrm{ml})$, amphiregulin (1000 ng/ml) and betacellulin (10 ng/ml and $1000 \mathrm{ng} / \mathrm{ml})$.

\section{Effect of combination of EGF with amphiregulin and/or} betacellulin on resumption of meiosis (Exp. 2)

Addition of amphiregulin and/or betacellulin to maturation medium containing EGF supplement increased the percentage of oocytes completing GVBD, although there were no different among the combined groups (Table 2). The incidence of oocytes matured to the metaphase-II stage also increased when amphiregulin or betacellulin was added to maturation medium containing EGF supplement. When both amphiregulin and betacellulin were added to maturation medium containing EGF, however, the percentage of oocytes at the metaphase-II stage did not differ from those of oocytes cultured in the presence of EGF alone and EGF plus amphiregulin or betacellulin. Since the variation in the incidence of oocytes matured to the metaphase-II stage was greater in the presence of EGF and betacellulin, rather than EGF and amphiregulin, the latter combination was utilized in the following experiments.
Effect of combination of EGF-family peptides with dibutyryl cAMP on resumption of meiosis (Exp. 3)

Exposure of COCs to dibutyryl cAMP alone during the first $20 \mathrm{~h}$ of IVM culture stimulated the incidences of oocytes completing GVBD and of oocytes maturing to the metaphase-II stage to the same level stimulated by EGF during the first $20 \mathrm{~h}$ of IVM culture (Table 3). However, addition of dibutyryl cAMP to maturation medium containing EGF supplement(s) increased the percentages of oocytes completing GVBD and of oocytes maturing to the metaphase-II stage. When COCs were exposed to dibutyryl cAMP and EGF during the first $20 \mathrm{~h}$ of IVM culture, the percentage of oocytes maturing to the metaphase-II stage was relatively similar to that of oocytes cultured in a standard IVM system with gonadotropins and dibutyryl cAMP $(\mathrm{P}=0.07)$. The presence of dibutyryl cAMP, EGF and amphiregulin during the first $20 \mathrm{~h}$ of IVM supports the percentages of oocytes completing GVBD and of oocytes maturing to the metaphase-II stage to the same level as oocytes cultured in a standard IVM system with gonadotropins and dibutyryl cAMP ( $\mathrm{P}=0.57$, Table 3 ). Thus, this combination of dibutyryl cAMP, EGF and amphiregulin was utilized in the following experiments.

In vitro maturation of denuded oocytes exposed to EGF-family peptides and/or dibutyryl cAMP (Exp. 4)

Exposure of cumulus-free oocytes to dibutyryl cAMP alone or in combination with EGF-family members, even in a standard IVM 
Table 4. In vitro maturation of denuded oocytes cultured with EGF-family peptides and/or dibutyryl cAMP in a gonadotropin-free medium*

\begin{tabular}{|c|c|c|c|c|c|c|}
\hline Supplements & $\begin{array}{l}\text { No. of oocytes } \\
\text { examined* }\end{array}$ & $\begin{array}{c}\% * * \text { oocytes } \\
\text { completing GVBD }\end{array}$ & $\begin{array}{c}\% * * \text { Pro M-I } \\
\text { oocytes }\end{array}$ & $\begin{array}{l}\% * * \text { M-I } \\
\text { oocytes }\end{array}$ & $\begin{array}{c}\% * * \text { A-I/T-I } \\
\text { oocytes }\end{array}$ & $\begin{array}{l}\% * * \text { M-II } \\
\text { oocytes }\end{array}$ \\
\hline None (negative control) & 77 & $36.1 \pm 5.9$ & $1.3 \pm 1.3$ & $6.4 \pm 3.4$ & 0 & $27.1 \pm 8.7$ \\
\hline Dibutyryl cAMP & 109 & $57.1 \pm 8.8$ & $4.5 \pm 2.6$ & $7.3 \pm 3.0$ & $3.8 \pm 1.8$ & $41.5 \pm 8.8$ \\
\hline EGF + amphiregulin & 77 & $50.5 \pm 8.1$ & $9.3 \pm 9.3$ & $1.1 \pm 1.1$ & 0 & $40.1 \pm 13.7$ \\
\hline EGF + amphiregulin + dibutyryl cAMP & 106 & $49.0 \pm 2.7$ & $1.9 \pm 1.1$ & $10.9 \pm 6.1$ & 0 & $36.2 \pm 6.4$ \\
\hline Positive control (Gns + dibutyryl cAMP & 93 & $52.0 \pm 13.7$ & $3.5 \pm 2.1$ & $11.9 \pm 4.4$ & $3.5 \pm 2.1$ & $33.1 \pm 7.8$ \\
\hline
\end{tabular}

*Denuded oocytes were cultured for $44 \mathrm{~h}$ in gonadotropin-free mPOM. EGF-family peptides (10 ng/ml EGF, $1000 \mathrm{ng} / \mathrm{ml}$ amphiregulin) and dibutyryl cAMP (1 mM), or gonadotropins (Gns; $10 \mathrm{U} / \mathrm{ml} \mathrm{eCG}$ and $10 \mathrm{U} / \mathrm{ml} \mathrm{hCG}$ ) and dibutyryl cAMP (1 mM) were added only for the first $20 \mathrm{~h}$ of culture. **Percentage based on the total number of oocytes examined. Data are presented as means \pm S.E.M. of three or four replicated experiments.

Table 5. In vitro development of oocytes matured in a gonadotropin-free chemically defined system following IVF

\begin{tabular}{lcccc}
\hline Experimental group & $\begin{array}{c}\text { No. of oocytes } \\
\text { inseminated* }\end{array}$ & $\begin{array}{c}\text { \%** oocytes } \\
\text { cleaved }\end{array}$ & $\begin{array}{c}\text { \%** oocytes developing } \\
\text { beyond the morula stage }\end{array}$ & $\begin{array}{c}\text { \%** oocytes developing } \\
\text { to the blastocyst }\end{array}$ \\
\hline Control (Gns + dibutyryl cAMP) & 92 & $74.9 \pm 16.0$ & $24.1 \pm 3.3$ & $17.3 \pm 4.2$ \\
EGF + amphiregulin + dibutyryl cAMP & 161 & $72.1 \pm 14.6$ & $33.9 \pm 6.0$ & $25.0 \pm 4.0$ \\
\hline
\end{tabular}

* COC were cultured in mPOM containing Gns (10 U/ml eCG and $10 \mathrm{U} / \mathrm{ml} \mathrm{hCG}) \pm 1 \mathrm{mM}$ dibutyryl cAMP or $10 \mathrm{ng} / \mathrm{ml} \mathrm{EGF} \pm 1000 \mathrm{ng} / \mathrm{ml}$ amphiregulin $\pm 1 \mathrm{mM}$ dibutyryl cAMP for $20 \mathrm{~h}$ and then without these supplements for $24 \mathrm{~h}$. Following in-vitro culture for maturation, the denuded oocytes were co-cultured with fresh spermatozoa for $8 \mathrm{~h}$ in PGM-tac4 and then cultured in PZM- 5 for 7 days. ** Percentage based on the number of oocytes inseminated. Data are presented as means \pm S.E.M. of three and six replicated experiments.

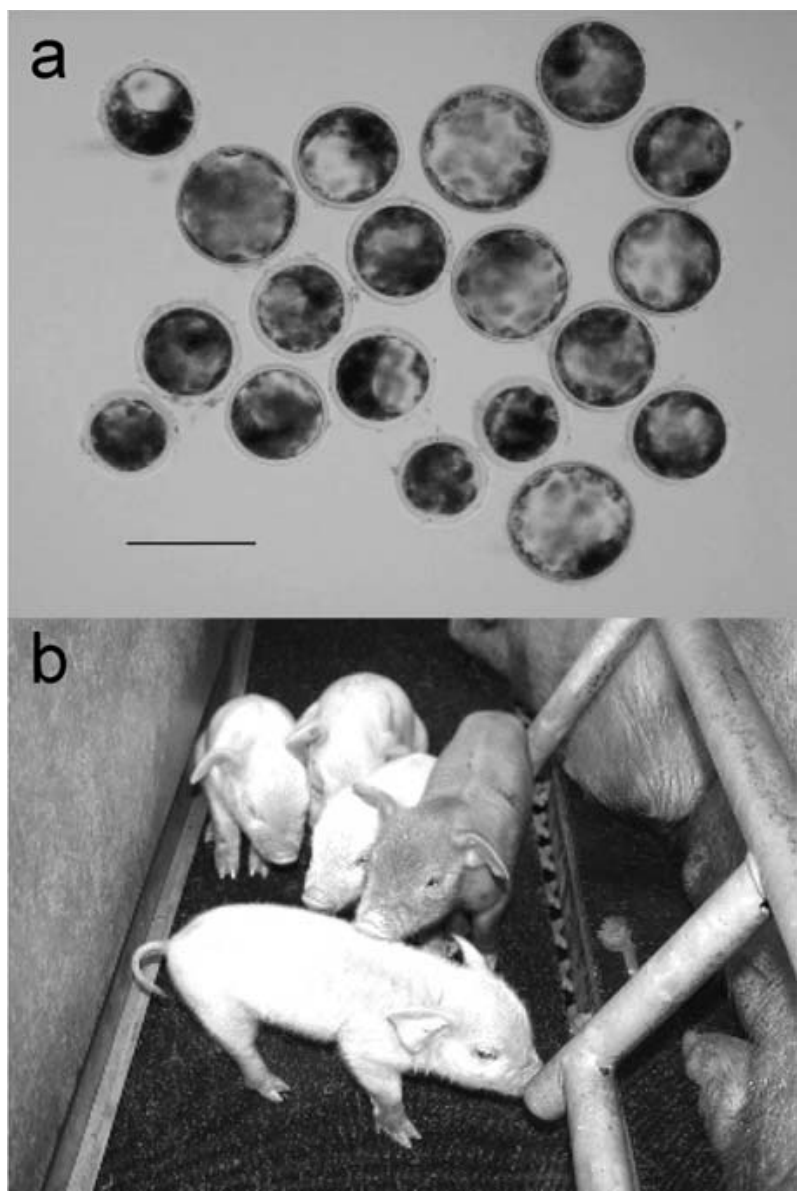

Fig. 1. a) Blastocysts transferred. The bar shows 200 micrometers. b) Piglets (one day old on December 31, 2008) obtained by transfer of blastocysts derived from oocytes matured in a gonadotropinfree IVM medium and fertilized and developed in chemically defined media.

system with gonadotropins and dibutyryl cAMP, did not affect the percentage of oocytes completing GVBD or the percentage of oocytes maturing to the metaphase-II stage (Table 4). However, there was a relatively higher tendency in the percentages of oocytes completing GVBD and maturing to the metaphase-II stage in the control denuded oocytes, as compared with the control COCs (Tables 1-3).

Developmental competence of oocytes matured in a gonadotropin-free IVM system (Exp. 5)

As shown in Table 5, there was no difference in developmental competence to the blastocyst stage following IVF between oocytes matured in a gonadotropin-free chemically defined system and those matured in a standard IVM system with gonadotropins. Following embryo transfer of blastocysts (Fig. 1a) produced in a gonadotropin-free chemically defined IVM-IVF-IVC system to three recipients, all of the recipients achieved pregnancy and farrowed a total of 11 piglets; of these, 10 were alive (Table 6, Fig. 1b). No clinical abnormalities were observed in the piglets that were born alive. The gestation lengths and body weights of the piglets were within the normal range (Table 6). 
Table 6. Result of transfer of blastocysts derived from IVF oocytes matured in a gonadotropin-free chemically defined system

\begin{tabular}{|c|c|c|c|c|c|}
\hline Recipient & $\begin{array}{l}\text { No. of embryos } \\
\text { transferred* }\end{array}$ & Pregnancy & $\begin{array}{l}\text { Gestation length } \\
\text { (days)* }\end{array}$ & $\begin{array}{l}\text { Total no. of piglets born } \\
\text { (No. of live piglets) }\end{array}$ & $\begin{array}{l}\text { Average body weight of } \\
\text { piglets at birth }(\mathrm{kg})\end{array}$ \\
\hline Z128 & 19 & Yes & 115 & $1(1)$ & 1.40 \\
\hline Z129 & 19 & Yes & 112 & $6(5)$ & $1.59 \pm 0.09$ \\
\hline Z130 & 18 & Yes & 114 & $4(4)$ & $1.26 \pm 0.17$ \\
\hline Overall - & $--\overline{56}--$ & & $-\overline{11} \overline{3} . \overline{7} \pm \overline{1} . \overline{1}$ & $--11(10)$ & $\overline{1.44} \pm \overline{0.09}$ \\
\hline
\end{tabular}

* Day $0=2$ days after hCG injection. Data are presented as means \pm S.E.M.

\section{Discussion}

This is the first report to document the birth of piglets from oocytes matured in a gonadotropin-free medium and fertilized and developed to the blastocyst stage in chemically defined media. Several studies have reported piglet production by surgical embryo transfer using IVM-IVF-IVC blastocysts [6, 23, 24]. In these reports, however, porcine oocytes were matured in media containing materials derived from other organisms, such as follicular fluid and/or gonadotropins. Recently, Yoshioka et al. have also produced blastocysts in the chemically defined IVF and IVC system from oocytes matured in a simple chemically defined medium supplemented with gonadotropins [5]. In the current study, we succeeded in improving the IVM system by making it gonadotropin-free. The efficiency of piglet production (the number of piglets produced per number of blastocysts transferred) was relatively high. This evidence indicates that the quality of the embryos produced by the current IVM-IVF-IVC system is enough to enable development to full term, suggesting the possibility of useful application of this gonadotropin-free IVM and chemically defined IVFIVC system for safe production of porcine embryos in vitro.

Potential factors that play roles in triggering oocyte maturation have been reported to include gonadotropins (e.g., FSH and LH), growth factors (e.g., amphiregulin and epiregulin) and sterols (e.g., follicular fluid-derived meiosis-activating sterol) [25]. In this study, we also found that EGF alone and in cooperation with dibutyryl cAMP has critical roles in resumption of meiosis and support of the nuclear and cytoplasmic maturation of porcine oocytes in gonadotropin-free chemically defined medium. In the present study, EGF and betacellulin affected stimulation of meiotic resumption and progression. EGF-family members, such as amphiregulin, epiregulin and betacellulin, are likely paracrine mediators of the LH signal in the horse [14] and rat [17]. In mice, deficit in either amphiregulin or epiregulin, two EGF receptor ligands, delays or reduces oocyte maturation and cumulus expansion [16]. LH stimulation induces the transient and sequential expression of EGF family members amphiregulin, epiregulin and betacellulin, and incubation of follicles with these growth factors recapitulates the morphological and biochemical events triggered by LH, including cumulus expansion and oocyte maturation [13]. The current observations confirm that the potential role of EGF-family members in oocyte maturation, as previously observed in other mammalian species, is also true in pigs. In the present study, EGF and betacellulin worked well at $10 \mathrm{ng} / \mathrm{ml}$, whereas amphiregulin was not effective at $10 \mathrm{ng} / \mathrm{ml}$, but was effective at $1000 \mathrm{ng} / \mathrm{ml}$. This difference in the effective concentration may be due to the difference in binding affinity, since the affinity of amphiregulin is several orders of magnitude less than that of EGF [26, 27].

Furthermore, it is very interesting that a combination of EGF with another EGF-family member (amphiregulin or betacellulin), as compared with EGF alone, improved the percentage of oocytes developing to the metaphase-II stage. A similar synergistic effect on oocyte maturation has been observed in buffalo COCs exposed to EGF plus IGF-I [28]. The EGF receptor family consists of four members: ErbB1, ErbB2, ErbB3 and ErbB4. The receptor of amphiregulin, as well as EGF, is ErbB1, whereas betacellulin binds to ErbB1 and ErbB4 [29]. Therefore, the common receptor of these EGF-family members should be ErbB1. However, the structure of the ectodomain fragment of ErbB1 resembles the corresponding domain of the insulin-like growth factor-1 (IGF-1) receptor [30]. Supplementation of IVM medium with IGF-1 is also well known to promote the incidence of porcine oocytes reaching the metaphaseII stage [31, 32], whereas the stimulating effect has been reported to be masked in the presence of EGF [33]. Furthermore, there is a positive relationship between the mean circulating concentrations of IGF-I during the follicular phase and the proportion of metaphase-II oocytes in pigs [34]. Therefore, the combination effect of EGF and amphiregulin or betacellulin in the current study may be due to a cross-linkage to the IGF-1 receptors, consequently increasing the percentage of oocytes progressing to the metaphaseII stage. Further experiments will be required to clarify this combination effect.

In the present study, we demonstrated that supplementation of a gonadotropin-free chemically defined medium with dibutyryl cAMP during the first $20 \mathrm{~h}$ of IVM significantly induced the meiotic resumption of oocytes. The incidence of oocytes completing GVBD was higher than that of oocytes cultured in a gonadotropinfree chemically defined IVM medium with EGF or amphiregulin alone, whereas the incidence of oocytes developed to the metaphase-II stage did not differ between these oocytes. In IVM medium containing gonadotropins, the effects of dibutyryl cAMP have been well documented. Treatment of prepubertal COCs with dibutyryl cAMP during the first half of IVM improves the synchronicity of meiotic resumption and progression [19] and the developmental competence of porcine oocytes following IVF [19, 20,35] by increasing the mitochondrial membrane potential and decreasing the incidence of apoptosis in preimplantation-stage porcine embryos [36]. This evidence shows that control of meiotic 
resumption in porcine oocytes is highly regulated by cAMP [37]. In the present study, we confirmed, in a chemically defined gonadotropin-free medium, that dibutyryl cAMP could regulate the meiotic resumption of porcine oocytes more effectively than EGFfamily peptides alone when COCs are exposed to dibutyryl cAMP or EGF-family peptides during the first $20 \mathrm{~h}$ of IVM. Intracellular cAMP appears to regulate meiotic resumption of oocytes through the signaling pathways involved in maturation promoting factor (MPF) activation [38].

In the current study, we also found a synergistic effect of dibutyryl cAMP and EGF-family peptides not only on meiotic resumption, but also on the regulation of meiotic progression to the metaphase-II stage in porcine oocytes. In particular, exposure of COCs to a combination of dibutyryl cAMP with EGF plus amphiregulin during the first $20 \mathrm{~h}$ of IVM improved both the incidences of meiotic resumption and progression to the metaphase-II stage to the same levels as oocytes treated with gonadotropins and dibutyryl cAMP. Therefore, our current observations indicate that both the cAMP and EGF pathways need to be stimulated for successful meiotic resumption of porcine oocytes in a chemically defined gonadotropin-free medium. The promotional activity of EGF on porcine oocyte maturation is independent of the cAMP pathway and probably mediated by the protein kinase C (PKC) pathway [39]. In fact, it has been reported that an EGF-family peptide, amphiregulin, dose-dependently stimulates meiotic resumption of porcine COCs maintained in meiotic arrest with dibutyryl cAMP [40]. Further research will be required to clarify whether stimulation of both the PKA and PKC pathways induces successful meiotic maturation of porcine oocytes and to clarify the regulating mechanisms of meiotic resumption and progression to the metaphase-II stage.

Furthermore, increased cAMP resulting from inhibition of PDE3 in oocytes blocks GVBD, whereas increased cAMP resulting from inhibition of PDE4 activates the mitogen-activated protein kinase (MAPK) pathway in cumulus cells, which is essential for GVBD induction [41]. Recently, meiotic resumption in porcine COCs has also been shown to be transiently blocked by adenosine monophospate-activated kinase in cumulus cells [42]. Under the current culture conditions, we demonstrated that treatment of denuded oocytes with dibutyryl cAMP for the first $20 \mathrm{~h}$ of IVM did not stimulate meiotic resumption and progression to the metaphase-II stage, whereas there was a tendency for relatively higher GVBD and maturation incidences in denuded oocytes. This evidence suggests that the positive synergistic effect of dibutyryl cAMP and EGF-family peptides on meiotic resumption and progression to the metaphaseII stage in porcine oocytes, as well as factors to maintain meiotic arrest, act via communication within the COC. Shimada et al. reported that cAMP appears to play an important role not only in meiotic resumption, but also in the regulation of meiotic progression beyond the metaphase-I stage in porcine oocytes when transported into oocytes from the cumulus cells via gap junctions [43]. Recently, it also has been reported that phosphatidylinositol 3-kinase-induced mitogen-activated protein kinase activation in cumulus cells mediates EDF-induced meiotic resumption in porcine COCs [44].

In conclusion, the current results indicate that meiotic resump- tion and progression to the metaphase-II stage could be induced in porcine oocytes when COCs were exposed to a combination of dibutyryl cAMP and EGF-family peptides during the first $20 \mathrm{~h}$ of IVM in a chemically defined gonadotropin-free medium. The developmental competence of the oocytes was normal since embryo transfer of the oocytes following IVF could produce piglets with a relatively high efficiency. Therefore, in a chemically defined gonadotropin-free medium, we would recommend addition of a combination of dibutyryl cAMP and EGF-family peptides during the first $20 \mathrm{~h}$ of porcine IVM.

\section{Acknowledgments}

This study was supported by a grant (AgriBio \#1605) from the Ministry of Agriculture, Forestry and Fisheries of Japan.

\section{References}

1. Day BN, Funahashi H. In vitro maturation and fertilization of pig oocytes. In: H. MR, Pursel VG, Norman HD (eds.), Beltsville Symposia in Agricultural Research XX. Biotechnology's Role in the Genetic Improvement of Farm Animals. Savoy, IL, USA American Society of Animal Science; 1996: 125-144.

2. Day BN. Reproductive biotechnologies: current status in porcine reproduction. Anim Reprod Sci 2000; 60-61: 161-172.

3. Funahashi H, Day BN. Advances in in vitro production of pig embryos. J Reprod Fertil Suppl 1997; 52: 271-283.

4. Abeydeera LR, Wang WH, Cantley TC, Rieke A, Murphy CN, Prather RS, Day BN Development and viability of pig oocytes matured in a protein-free medium containing epidermal growth factor. Theriogenology 2000; 54: 787-797.

5. Yoshioka K, Suzuki C, Onishi A. Defined system for in vitro production of porcine embryos using a single basic medium. J Reprod Dev 2008; 54: 208-213.

6. Yoshioka K, Suzuki C, Itoh S, Kikuchi K, Iwamura S, Rodriguez Martinez H. Production of piglets derived from in vitro-produced blastocysts fertilizaed and cultured in chemically defined media: effects of theophylline, adenosine, and cysteine during in vitro fertilization. Biol Reprod 2003; 69: 2092-2099.

7. Suzuki C, Iwamura S, Yoshioka K. Birth of piglets through the non-surgical transfer of blastocysts produced in vitro. J Reprod Dev 2004; 50: 487-491.

8. Yoshioka K, Suzuki C, Tanaka A, Anas IM, Iwamura S. Birth of piglets derived from porcine zygotes cultured in a chemically defined medium. Biol Reprod 2002; 66: 112 119.

9. Schoevers EJ, Colenbrander B, Roelen BAJ. Developmental stage of the oocyte during antral follicle growth and cumulus investment determines in vitro embryo development of sow oocytes. Theriogenology 2007; 67: 1108-1122.

10. Ozawa M, Nagai T, Somfai T, Nakai M, Maedomari N, Fahrudin M, Karja NW, Kaneko H, Noguchi J, Ohnuma K, Yoshimi N, Miyazaki H, Kikuchi K. Comparison between effects of 3-isobutyl-1-methylxanthine and FSH on gap junctional communication, LH-receptor expression, and meiotic maturation of cumulus-oocyte complexes in pigs. Mol Reprod Dev 2008; 75: 857-866.

11. Funahashi H, Day BN. Effects of the duration of exposure to hormone supplements on cytoplasmic maturation of pig oocytes in vitro. J Reprod Fertil 1993; 98: 179-185.

12. Shimada $\mathbf{M}$, Nishibori $\mathbf{M}$, Isobe $\mathbf{N}$, Kawano $\mathbf{N}$, Terada $\mathbf{T}$. Luteinizing hormone receptor formation in cumulus cells surrounding porcine oocytes and its role during meiotic maturation of porcine oocytes. Biol Reprod 2003; 68: 1142-1149.

13. Park JY, Su YQ, Ariga M, Law E, Jin SL, Conti M. EGF-like growth factors as mediators of LH action in the ovulatory follicle. Science 2004; 303: 682-684.

14. Lindbloom SM, Farmerie TA, Clay CM, Seidel GE, Jr., Carnevale EM. Potential involvement of EGF-like growth factors and phosphodiesterases in initiation of equine oocyte maturation. Anim Reprod Sci 2008; 103: 187-192.

15. Ben-Ami I, Freimann S, Armon L, Dantes A, Ron-El R, Amsterdam A. Novel function of ovarian growth factors: combined studies by DNA microarray, biochemical and physiological approaches. Mol Hum Reprod 2006; 12: 413-419.

16. Hsieh M, Lee D, Panigone S, Horner K, Chen R, Theologis A, Lee DC, Threadgill DW, Conti M. Luteinizing hormone-dependent activation of the epidermal growth factor network is essential for ovulation. Mol Cell Biol 2007; 27: 1914-1924.

17. Ashkenazi H, Cao X, Motola S, Popliker M, Conti M, Tsafriri A. Epidermal growth factor family members: Endogenous mediators of the ovulatory response. Endocrinology $2005 ; 146: 77-84$ 
18. Abeydeera LR, Wang WH, Cantley TC, Rieke A, Prather RS, Day BN. Presence of epidermal growth factor during in vitro maturation of pig oocytes and embryo culture can modulate blastocyst development after in vitro fertilization. Mol Reprod Dev 1998; 51: 395-401.

19. Funahashi H, Cantley TC, Day BN. Synchronization of meiosis in porcine oocytes by exposure to dibutyryl cyclic adenosine monophosphate improves developmental competence following in vitro fertilization. Biol Reprod 1997; 57: 49-53.

20. Bagg MA, Nottle MB, Grupen CG, Armstrong DT. Effect of dibutyryl cAMP on the cAMP content, meiotic progression, and developmental potential of in vitro matured pre-pubertal and adult pig oocytes. Mol Reprod Dev 2006; 73: 1326-1332.

21. Funahashi $\mathbf{H}$, Sano $\mathbf{T}$. Select antioxidants improve the function of extended boar semen stored at 10 degrees C. Theriogenology 2005; 63: 1605-1616.

22. Funahashi H, Cantley TC, Day BN. Different hormonal requirement of porcine oocyte-complexes during maturation in vitro. J Reprod Fertil 1994; 101: 159-165.

23. Kikuchi K, Onishi A, Kashiwazaki N, Iwamoto M, Noguchi J, Kaneko H, Akita T, Nagai T. Successful piglet production after transfer of blastocysts produced by a modified in vitro system. Biol Reprod 2002; 66: 1033-1041.

24. Marchal R, Feugang JM, Perreau C, Venturi E, Terqui M, Mermillod P. Meiotic and developmental competence of prepubertal and adult swine oocytes. Theriogenology 2001; 56: 17-29.

25. Jamnongjit M, Hammes SR. Oocyte maturation: the coming of age of a germ cell. Seminars in Reprod Med 2005; 23: 234-241.

26. Thompson SA, Harris A, Hoang D, Ferrer M, Johnson GR. COOH-terminal extended recombinant amphiregulin with bioactivity comparable with naturally derived growth factor. J Biol Chem 1996; 271: 17927-17931.

27. Neelam B, Richter A, Chamberlin SG, Puddicombe SM, Wood L, Murray MB, Nandagopal K, Niyogi SK, Davies DE. Structure-function studies of ligand-induced epidermal growth factor receptor dimerization. Biochemistry 1998; 37: 4884-4891.

28. Purohit GN, Brady MS, Sharma SS. Influence of epidermal growth factor and insulin-like growth factor 1 on nuclear maturation and fertilization of buffalo cumulus oocyte complexes in serum free media and their subsequent development in vitro. Anim Reprod Sci 2005; 87: 229-239.

29. Dreux AC, Lamb DJ, Modjtahedi H, Ferns GA. The epidermal growth factor receptors and their family of ligands: their putative role in atherogenesis. Atherosclerosis 2006; 186: 38-53.

30. Jorissen RN, Walker F, Pouliot N, Garrett TP, Ward CW, Burgess AW. Epidermal growth factor receptor: mechanisms of activation and signalling. Exp Cell Res 2003; 284: 31-53.

31. Sirotkin AV, Dukesova J, Makarevich AV, Kubek A, Bulla J. Evidence that growth factors IGF-I, IGF-II and EGF can stimulate nuclear maturation of porcine oocytes via intracellular protein kinase A. Reprod Nutr Dev 2000; 40: 559-569.

32. Sirotkin AV, Taradajnik TE, Makarevich AV, Bulla J. Effect of follicular cells, IGF-I and tyrosine kinase blockers on oocyte maturation. Anim Reprod Sci 1998; 51: 333-344.

33. Grupen CG, Nagashima H, Nottle MB. Role of epidermal growth factor and insulinlike growth factor-I on porcine oocyte maturation and embryonic development in vitro. Reprod Fertil Dev 1997; 9: 571-575.

34. Ferguson EM, Ashworth CJ, Edwards SA, Hawkins N, Hepburn N, Hunter MG Effect of different nutritional regimens before ovulation on plasma concentrations of metabolic and reproductive hormones and oocyte maturation in gilts. Reproduction 2003; 126: 61-71.

35. Bagg MA, Nottle MB, Armstrong DT, Grupen CG. Relationship between follicle size and oocyte developmental competence in prepubertal and adult pigs. Reprod Fertil Dev 2007; 19: 797-803.

36. Kim JS, Cho YS, Song BS, Wee G, Park JS, Choo YK, Yu K, Lee KK, Han YM, Koo DB. Exogenous dibutyryl cAMP affects meiotic maturation via protein kinase A activation; it stimulates further embryonic development including blastocyst quality in pigs. Theriogenology 2008; 69: 290-301.

37. Laforest MF, Pouliot E, Gueguen L, Richard FJ. Fundamental significance of specific phosphodiesterases in the control of spontaneous meiotic resumption in porcine oocytes. Mol Reprod Dev 2005; 70: 361-372.

38. Morikawa M, Seki M, Kume S, Endo T, Nishimura Y, Kano K, Naito K. Meiotic resumption of porcine immature oocytes is prevented by ooplasmic Gsalpha functions. J Reprod Dev 2007; 53: 1151-1157.

39. Coskun S, Lin YC. Mechanism of action of epidermal growth factor-induced porcine oocyte maturation. Mol Reprod Dev 1995; 42: 311-317.

40. Downs SM, Chen J. EGF-like peptides mediate FSH-induced maturation of cumulus cell-enclosed mouse oocytes. Mol Reprod Dev 2008; 75: 105-114.

41. Liang CG, Huo LJ, Zhong ZS, Chen DY, Schatten H, Sun QY. Cyclic adenosine 3',5'monophosphate-dependent activation of mitogen-activated protein kinase in cumulus cells is essential for germinal vesicle breakdown of porcine cumulus-enclosed oocytes. Endocrinology 2005; 146: 4437-4444.

42. Mayes MA, Laforest MF, Guillemette C, Gilchrist RB, Richard FJ. Adenosine 5' monophosphate kinase-activated protein kinase (PRKA) activators delay meiotic resumption in porcine oocytes. Biol Reprod 2007; 76: 589-597.

43. Shimada $\mathbf{M}$, Terada T. Roles of cAMP in regulation of both MAP kinase and p34(cdc2) kinase activity during meiotic progression, especially beyond the MI stage. Mol Reprod Dev 2002; 62: 124-131.

44. Li M, Liang CG, Xiong B, Xu BZ, Lin SL, Hou Y, Chen DY, Schatten H, Sun QY. PI3kinase and mitogen-activated protein kinase in cumulus cells mediate EGF-induced meiotic resumption of porcine oocyte. Domestic Anim Endocrinol 2008; 34: 360-371. 